\title{
DROOP CONTROL METHOD FOR PARALLEL DC CONVERTERS USED IN STANDALONE PV-WIND POWER GENERATING SYSTEM
}

\author{
Reshma Mary Thomas ${ }^{1}$, Deepu Jose ${ }^{2}$ \\ ${ }^{1}$ M.Tech Student, Department Electrical Engineering-Power Systems, Saintgits College of Engineering, Kerala, India \\ ${ }^{2}$ Assistant Professor, Saintgits College of Engineering, Kerala, India
}

\begin{abstract}
The rising rate of consumption and price of fossil fuel along with environmental pollution by conventional power generation draw global attention to renewable energy sources and technology. Paper gives analysis study on current sharing issues of parallel DC converters in standalone photovoltaic (PV) WIND system. Solar wind power generating system with maximum power point tracking (MPPT) technique - incremental conductance method is used for the simulation analysis. The main drawbacks of parallel converters used in system are poor power sharing and voltage drop. The paper describes about instantaneous droop calculation considering effect of cable resistance using droop index to improve the power sharing performance. The control technique is simulated using MATLAB/SIMULINK in PV-wind power generating system with MPPT and case study has been done on the control strategy and verifies the effectiveness of adaptive droop control on output converter voltage.
\end{abstract}

Key Words: Microgrid; droop method; incremental conductance (Incond); maximum power point tracking (MPPT).

\section{INTRODUCTION}

The demand on electrical energy is increasing day by day. For our future demand the existing energy systems will not be enough. Therefore the search for alternative energy sources has become an important issue. Many researches has been done in the area of unlimited energy resources such as wind power generation and solar energy transformation. Also expensive technologies and global environmental damage techniques has led to a global scenario which point towards generating clean and eco-friendly green energy. In many ways, green energy is having a leading role in the democratized energy production and consumption in the country. Of all the renewable energy sources, solar energy have the least impact on environmental. Electricity produced from photovoltaic (PV) cells does not result in environmental pollution, deplete natural resources, or endanger living being [1].

For many years, the centralized power grid is one way of electricity flow, generated by large, remote power plants and distributed over large distance by transmission lines to homes and industries. In recent years the system's shortcomings are increasing. The traditional grid is highly depends on planet-warming fossil fuels. Due to the upcoming of negative issues there is departing from the traditional system and introduced a new model called Microgrid. A microgrid is independent systems that produce power for a specific entity. A microgrid is defined by the ability to generate power using renewable energy sources near or at the point of consumption independent of other generators. Main applications are in areas having high energy prices or remote areas (such as islands) or facilities, such as military or experimental installations that cannot risk losing power, etc. Microgrid, also named as minigrids, can be operated in islanded or grid connected mode.
Compared to AC, DC microgrids are very reliable highly efficient, economic and easy to control.

The main problem faced by the DC Microgrid is that when converters are parallel connected the output voltage from converter won't be constant always. [2]- [8] Main reason for this variation is due to change in load and input power and also feedback voltage and current. Even a small mismatch of output voltage will initiate circulating current and difference in current sharing will cause an overload to the converters and also variation in power sharing. The converter with higher output voltage will give higher power. One of most popular control technique for proper sharing is droop control method. This paper mainly focus on the voltage control and power sharing of the converters using droop index and also maximum power point tracking for better performance.

The droop control method is a decentralized control technique in which each converter is controlled based on the output current [7]. This paper explains the importance of cable resistance in load sharing. In existing methods the droop used for voltage control is fixed which a major drawback [5]. An instantaneous droop is calculated to overcome this drawback which can improve the voltage control to larger extend.

The droop control method is local control technique that relies on externally or internally added resistance of the parallel connected modules for maintaining relatively equal current sharing. Generally, the droop method is easy to implement, and it does not require any communication system. However, fixed droop method also achieves the equivalent current sharing accuracy but major drawback is its poor voltage regulation whereas in case of instantaneously produced droop, it can adaptively controls the reference voltage of each module.[10]-[12] This will improve the voltage regulation and the current sharing of the traditional method. 
The solar cell and wind turbine efficiency depends on factors such as temperature, insolation (radiation), dirt, shadow, wind speed and so on. Due to fast changing climate such as cloudy weather, storm or sunny day there will be changes in irradiance, wind speed and rise in ambient temperature can decrease the PV wind output power. PV wind system produces energy depending to its operational and environmental conditions. Maximum power point tracking (MPPT) is a concept put forward to improve the efficiency of PV - wind system. All MPPT methods follow goal of maximizing the output power by tracking the maximum on all operating condition. Analysis study and case study of the droop control method for voltage regulation and MPPT method is explained.

\section{SOLAR - WIND ENERGY CONVERSION SYSTEM WITH MPPT}

\subsection{Solar Cell}

A PV cell is basic unit of solar module. By photoelectric phenomenon the solar cell converts light energy into electricity. A single PV cell can produce only a small amount of energy. To increase the output of the system, solar cells are usually connected in parallel or series to form PV array. Figure 1 shows the simplified circuit diagram of a PV cell. The main equation of the output current of a module is

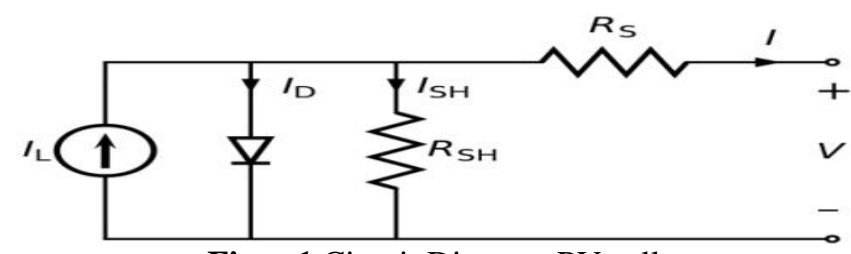

Fig -: 1 Circuit Diagram PV cell

$\mathrm{I}_{0}=\operatorname{npIp} h-\operatorname{npIrs}\left[\exp \left(\mathrm{k} 0 \frac{\mathrm{V}}{\mathrm{n}_{\mathrm{s}}}\right)-1\right]$

where $\mathrm{I} o$ is output PV current, V is the output PV voltage, cell photocurrent, Irs, solar cell reverse saturation current Iph which is proportional to solar irradiation, that mainly depends on surrounding temperature, $\mathrm{k} o$ is constant, $n p$ represents number of cell connected in parallel and $n s$ represent the number of series connected PV cells.

\subsection{Wind energy subsystem}

Wind energy conversion subsystem mainly consists of different electrical and mechanical components which include a wind turbine, a generator, power conversion components, and controllers. Three blades turbines are the most common wind turbines that can rotate and transmit the rotation to an electrical generator through out a gear box velocity conversion system. Generators have different types such as synchronous generators, permanent magnet and induction generators.

MPPT is an electronic system which controls the converters' duty cycle circuit and enables the system to operate at maximum power at all operating condition. The benefits of
MPPT regulators are greatest during cloudy or hazy days. There are different types of MPPT methods developed are (1) Incremental conductance method, (2) Perturb and observe method, (3) Artificial neutral network method.

\subsection{Incremental conductance method}

The incremental conductance method of MPPT is based on the incremental and instantaneous conductance.

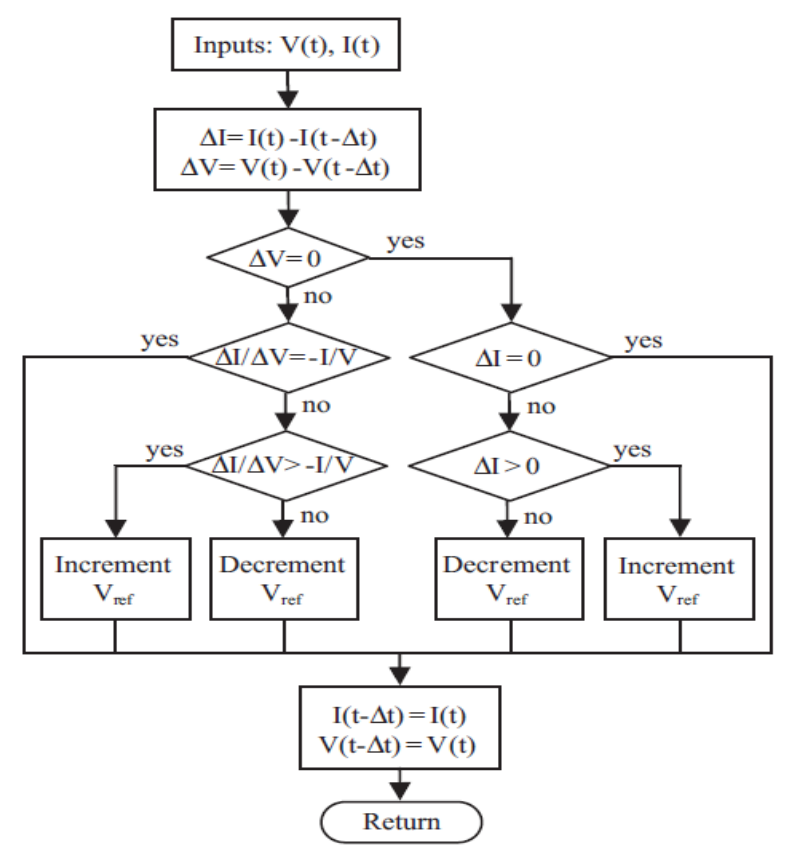

Fig -: 1. Algorithm of InCond method

When MPPT has reached the maximum point by using the InCond method then it will stop perturbing at the operating point. If this condition is not satisfied, the direction in which the MPPT operating point must be perturbed can be obtain using the relationship between $\frac{\delta I}{\delta V}$ and $-\frac{I}{V}$. Inc cond have advantages over $\mathrm{P} \& \mathrm{O}$ method that is it can determine when the MPPT has reached the maximum power. But in case of $\mathrm{P} \& \mathrm{O}$, it oscillates around the maximum power point. Also, Incond method can track rapidly changing (increasing or decreasing) climatic conditions with higher accuracy than $\mathrm{P}$ $\& \mathrm{O}$ method.

The maximum output power,

$P_{M P P}=V_{M P P} I_{M P P}$

is calculated by differentiating output power with respect to voltage and then setting the result to zero. At MPP, as $\partial \mathrm{P} / \partial \mathrm{V}=0$. This equation can be written in terms of array voltage $\mathrm{V}$ and current $\mathrm{I}$ as

$\frac{\delta I}{\delta V}=-\frac{I}{V}$

\section{PARALLEL DC- DC BOOST CONVERTERS}

The DC-DC boost converters are used where the output voltage needed to be higher than the source voltage. The control technique used is sliding mode control. Sliding mode controller maintains stability and consistence performance in the face of modeling imprecision. Control gains used are 0.149 and 1.35 . 
TABLE -1:DC-DC BOOST CONVERTER PARAMETERS

\begin{tabular}{|l|l|}
\hline Parameters & Values \\
\hline Output power & 96 \\
\hline Output voltage & 48 \\
\hline Filter inductor & $710 \mu \mathrm{H}$ \\
\hline ESR of filter inductor & $0.03 \Omega$ \\
\hline Filter capacitor & $2220 \mu \mathrm{F}$ \\
\hline ESR of filter capacitor & $0.05 \Omega$ \\
\hline $\begin{array}{l}\text { Nominal switching } \\
\text { frequency }\end{array}$ & $100 \mathrm{kHz}$ \\
\hline
\end{tabular}

\subsection{Mathematical Analysis Of Circulating Current}

\section{For Two Parallel Connected Converters}

When converters are connected in parallel and if there is change in power output, then this will cause mismatch in converter output voltage which will in turn cause circulating current. Circulating current will increase the flow current through the switches which will increase the power electronic switch ratings and loses and cause overload to converters. This section explains load current sharing and circulating current issues for parallel DC-DC converters connected to a low-voltage dc microgrid. Fig. 3 shows simplified diagram of two parallel connected DC - DC converters. Output voltages, cable resistance and output currents of converter- 1 and converter- 2 are represented using $V_{D C 1}, V_{D C 2}, R_{1}$ and $R_{2}, I_{1}$ and $I_{2}$ respectively. $I_{C 12}$ is the circulating current component from converter-1 to converter- 2 and load current component from converter- 1 is $I_{1}{ }^{\prime}$.

By applying Kirchhoff's voltage law, the expression for output converter currents can be derived from equation and circulating current can be calculated.

$V_{D C 1}-I_{1} R_{1}-I_{L} R_{L}=0$

$V_{D C 2}-I_{2} R_{2}-I_{L} R_{L}=0$.

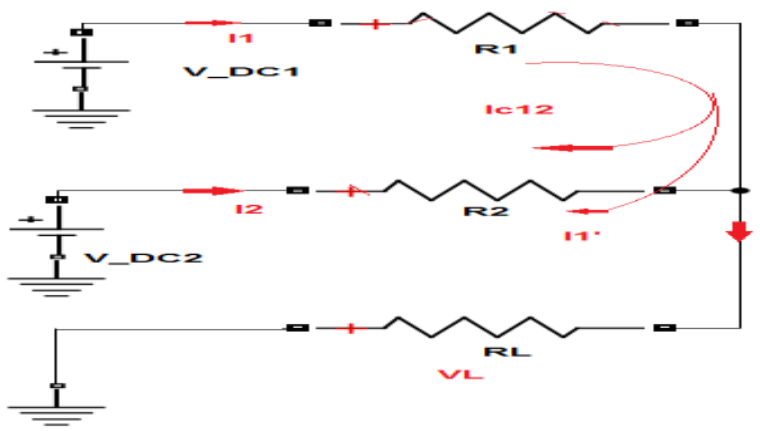

Fig -: 2. Equivalent circuit for DC output side

The expression for output converter currents $I_{1}$ and $I_{2}$ can be derived from equation (4) and (5) and circulating current is given as:

$I_{1}=\frac{\left(R_{2}+R_{L}\right) V_{D C 1}-\left(R_{L}\right) V_{D C 2}}{R_{1} R_{2}+R_{1} R_{L}+R_{2} R_{L}}$

$I_{2}=\frac{\left(R_{1}+R_{L}\right) V_{D C 2}-\left(R_{L}\right) V_{D C 1}}{R_{1} R_{2}+R_{1} R_{L}+R_{2} R_{L}}$

$I_{C 12}=\frac{V_{D C 1}-V_{D C 2}}{R_{1}+R_{2}}=\frac{I_{1} R_{1}-I_{2} R_{2}}{R_{1}+R_{2}}=\frac{I_{1}-I_{2}}{2} \quad\left(R_{1}=R_{2}\right)$

\section{VOLTAGE REGULATION AND CIRCULATING CURRENT CONTROL BY FIXED DROOP METHOD}

This section explains converter voltage regulation and minimization of circulating current by adding a series resistor, $\mathrm{R}_{\text {droop }}$ to each converter output as shown in Fig.2. $\mathrm{R}_{\text {droop }}$ is implemented using virtual impedance method. Fig4. By adding $\mathrm{R}_{\mathrm{droop} 1}$ and $\mathrm{R}_{\text {droop2 }}$ the current sharing can be controlled and thus circulating currents can be minimized to some extent. This can be done by taking output current from converters and multiplied with corresponding $\mathrm{R}_{\text {droop }}$. Then the resultant signal is subtracted from the reference voltage of each corresponding converter give new voltage reference signal.

$V_{D C \text { new }}=V_{D C}-\mathrm{I} R_{\text {droop }}$

But this method has still got drawbacks as it's a fixed value and therefore the voltage regulation will be poor.

\subsection{Adaptive Droop Control Method}

Instantaneous method for droop calculation for voltage regulation and circulating current minimization is explained in this section.

As we have seen in above equation (8) in two parallel converters, circulating current directly proportional to the current sharing difference.

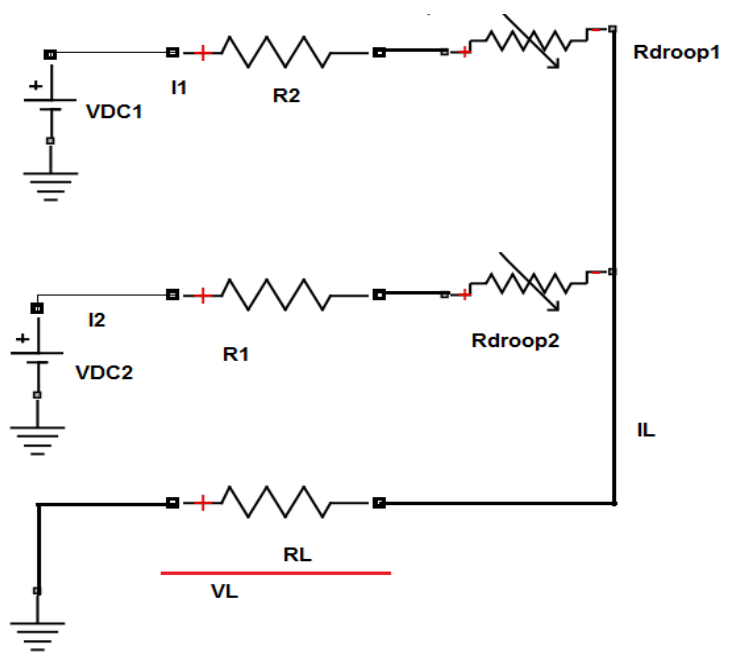

Fig -: 3. Equivalent circuit for DC output side with Rdroop

If the current sharing is equal then the resultant circulating current becomes zero. There will constant output voltage from converters. But simultaneous insertion of the series resistor will cause additional power loss in the system and it will lead to drop in the load voltage. $\mathrm{R}_{\mathrm{droop} 1}$ and $\mathrm{R}_{\text {droop2 }}$ are corresponding droop value of each converter. The output power loss can be expressed as,

$P_{\text {loss }}=I_{1}{ }^{2}\left(R_{1}+R_{\text {droop }}\right)+I_{2}{ }^{2}\left(R_{2}+R_{\text {droop }}\right)$ 
Calculation of droop values based on the proposed figureof-merit called droop index. The droop index is considered function of normalized current sharing difference and output power losses based on the need of voltage regulation issues and are given as

Droop Index $=\min \left[\frac{1}{2}\left|I_{1}-I_{2}\right|_{N}+\left(P_{\text {loss }}\right)_{N}\right]$

The current sharing and power loss equation can be modified in terms of parameters of second converter by introducing new variables $x, y$ and $m$ and given as

$$
\begin{gathered}
x=\frac{V_{D C 1}}{V_{D C 2}}, \\
y=\frac{R_{1}}{R_{2}}, \\
m=R_{2}+R_{\text {droop } 2} \\
\left|I_{1}-I_{2}\right|=\left|\frac{y\left(R_{2}+R_{\text {droop } 2}+R_{L}\right) V_{D C 2}-2(x-1) V_{D C 2} R_{L}}{m^{2} y+m R_{L}(y+1)}\right|
\end{gathered}
$$

Using the modified equation of circulating current and power loss the minimum droop index is calculated. $R_{\text {droop }}$ value for corressponding converter is selected in such way that $R_{\text {droop }}$, it is varied from zero and corresponding droop index value is noted and $R_{\text {droop }}$ value for minmum droop index is selected for further procedure. For the calculation of minimum droop index by varying $R_{\text {droop }}$, the product of converter output current and $R_{\text {droop }}$ should not increase the maximum allowable voltage deviation $( \pm 5 \%$ nominal voltage).

$R_{\text {droop } 2}$ Value for minimum droop index value of converter2 is droop value. Now the droop value for converter 1 can be calculated using

$$
R_{\text {droop } 1}=\left[\frac{R_{1}}{R_{2}}\right] R_{\text {droop } 2}
$$

The calculated droop value is may not be enough for voltage regulation. Therefore fine tuning of value is required to make the output voltage same but since the value is positive further increase will cause poor load voltage. To avoid this problem $R_{\text {droop }}$ shifting is done. $R_{\text {droop }}$ Shifting is done bases of the converter output value.

If the difference between converter output voltage is positive then ie;

$V_{D C 1}>V_{D C 2}$ then,

$R_{\text {droop 1 1 new }}=R_{\text {droop } 1}+\left(k_{1} * I_{L}\right)$

$R_{\text {droop } 2 \text { new }}=R_{\text {droop } 2}-\left(k_{2} * I_{L}\right)$

If the difference between converter output voltage is negative then ie;

$V_{D C 1}<V_{D C 2}$ then,

$R_{\text {droop 1 new }}=R_{\text {droop } 1}-\left(k_{2} * I_{L}\right)$

$R_{\text {droop } 2 \text { new }}=R_{\text {droop } 2}+\left(k_{1} * I_{L}\right)$
And if the converter output voltage values are equal then the corresponding droop values same as before. The droop correction factor $k_{1}$ and $k_{2}$ (0.001 and 0.02 respectively) should be selected such that $k_{1}<k_{2}$ to maintain load voltage within the limit.

\section{SIMULATION}

To check the performance of the droop control method in different cases, two parallel DC -DC boost converters (24V$48 \mathrm{~V}$ ) with solar energy as source has been simulated using MATLAB/SIMULINK. The output cable resistance is $100 \mathrm{~m} \Omega$ for each converter. The control algorithm is verified for the following cases, (i) Step change in output voltage of any one converter with both converters with same cable resistance (a) without droop control Fig.5. (b) With $R_{\text {droop }}$ control method.Fig.7.

Initially up to $1.101 \mathrm{~s}$ the simulation is done with nominal value, $48 \mathrm{~V}$. During time 1.101-1.3s the converter2 voltage value is increase by $1 \%$ of nominal value, $48.48 \mathrm{~V}$ and at time $1.301 \mathrm{~s}$ the voltage is brought back to $48 \mathrm{~V}$.

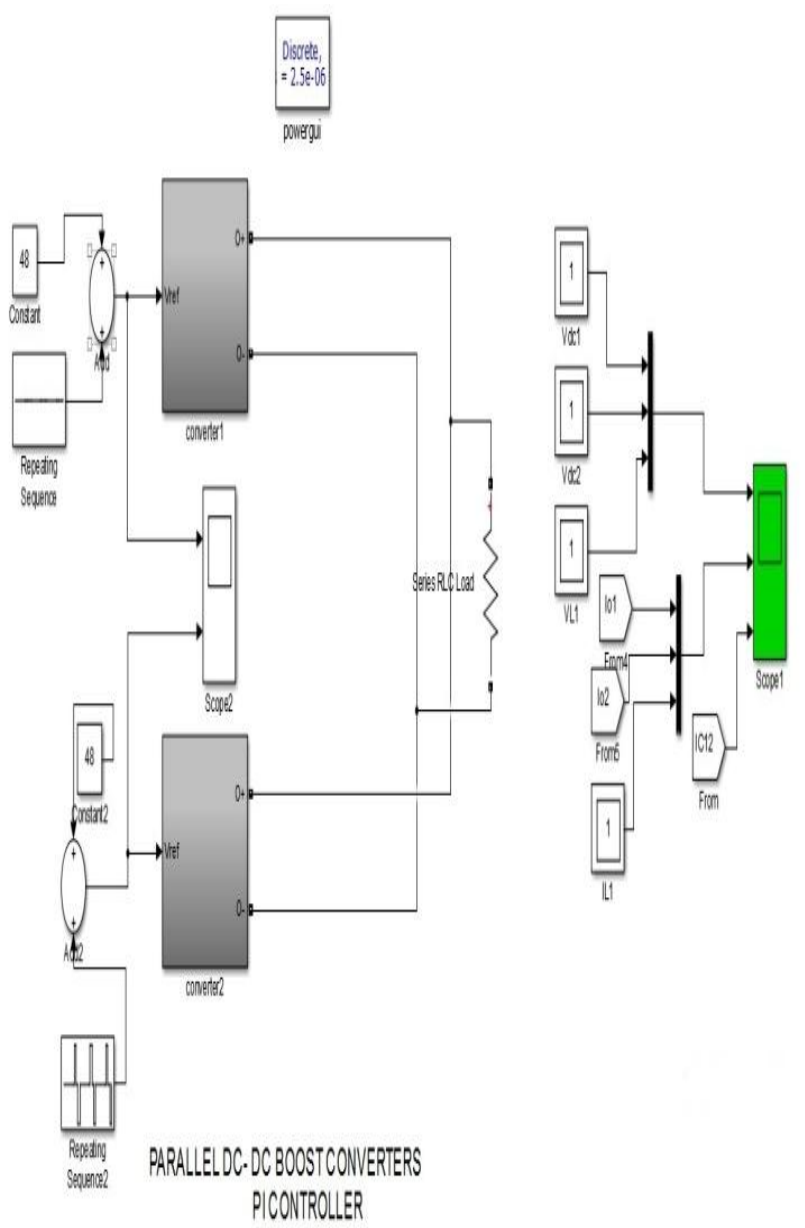

Fig -: 4 Simulink Model of Parallel converters without Droop

Then again during time $1.501-1.7 \mathrm{~s}$ the value is decreased by $1 \%$ of the nominal value, $47.52 \mathrm{~V}$. Then for the rest of the simulation time the voltage of converter is again brought back to nominal voltage. 

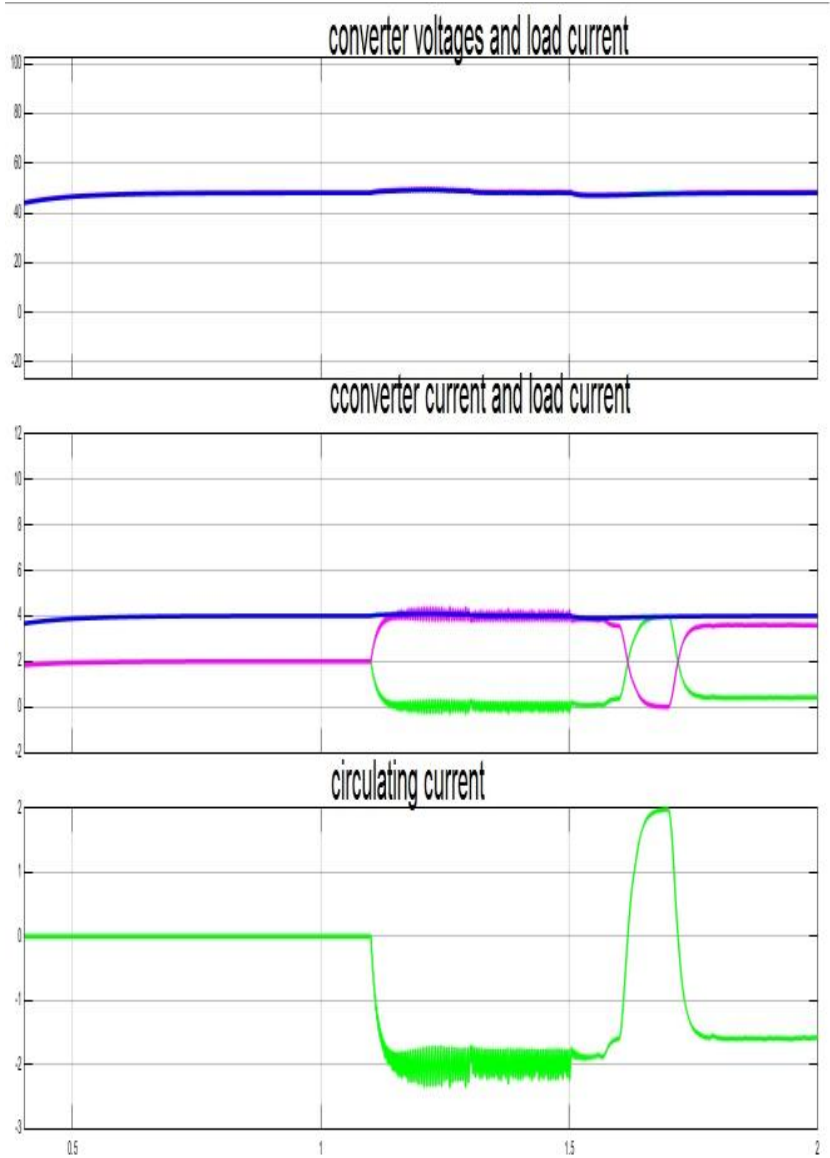

Fig -: 5. Simulation Result of without droop (a) converter output voltages and load voltage (b) converter output current and load current (c) circulating current.

From simulation result fig.6. of without droop, it can observe that the sharing is not proper and has a current sharing error of $25 \%$.

TABLE -2: SIMULATION RESULTS WITHOUT DROOP

\begin{tabular}{|l|l|l|l|}
\hline \multirow{2}{*}{ Time } & \multicolumn{3}{|l|}{ Output values } \\
\cline { 2 - 4 } & \multicolumn{1}{|l|}{$\boldsymbol{V d c 1 , V \boldsymbol { d } \boldsymbol { c } 2 , \boldsymbol { V } \boldsymbol { l } ( \boldsymbol { V } )}$} & $\begin{array}{l}\boldsymbol{I 1 , I 2 , I l} \\
(\boldsymbol{A})\end{array}$ & $\begin{array}{l}|\boldsymbol{I c 1 2}| \\
(\boldsymbol{A})\end{array}$ \\
\hline $0-1.101$ & $48,48,47.5$ & $2,2,4$ & 0 \\
\hline $1.101-1.3$ & $48,48.48,47.4$ & $0.1,3.9,4$ & 1.9 \\
\hline $1.501-1.7$ & $48,47.52,47.4$ & $3.9,0.1,4$ & 1.9 \\
\hline
\end{tabular}

For simulation with novel droop control method, the $R_{\text {droop } 1}$ and $R_{\text {droop } 2}$ values are calculated as $0.2 \Omega$ and still there is mismatch output converter voltage.After fine tuning of $R_{\text {droop }}$ voltage is not regulated completely. Then instantaneous value of $R_{\text {droop new }}$ is introduced with droop shifting which can improve the current sharing and the output converter voltage to a constant. Same simulation pattern is followed for the simulation with droop case as well.

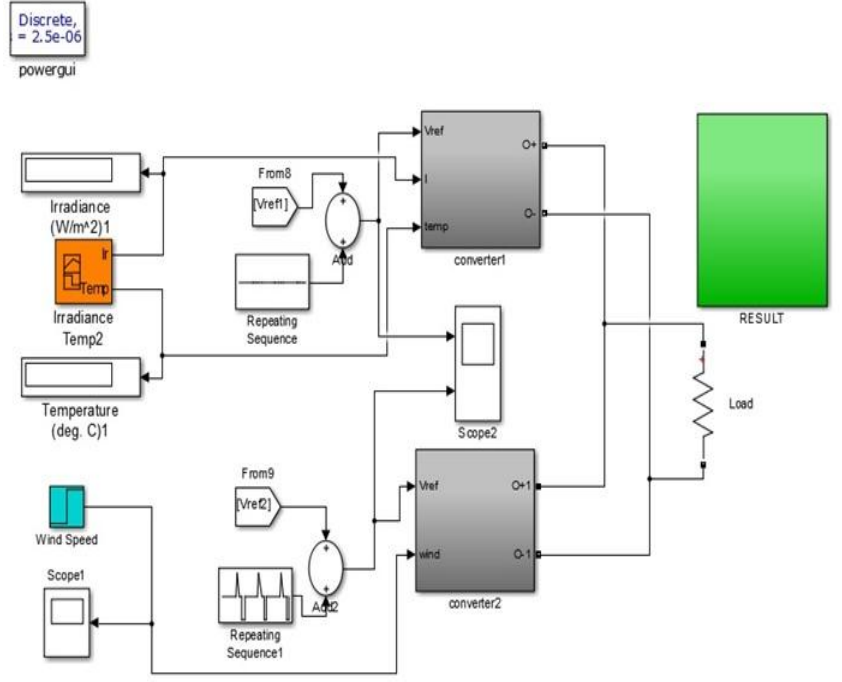

Fig -: 6 Simulink Model PV wind System with Droop Control

From the above simulation studies, fig. 8 . it can be seen that droop control method gives proper load sharing with minimum circulating current and improves load voltage.

TABLE I. SIMULATION RESULT WITH DROOP CONTROL.

\begin{tabular}{|c|c|c|c|}
\hline \multirow[b]{2}{*}{ Time } & \multicolumn{3}{|l|}{ Output values } \\
\hline & $\begin{array}{l}V d c 1, V d c 2, V l \\
(V)\end{array}$ & $I 1, I 2, I l(A)$ & $|\operatorname{Ic12}|(A)$ \\
\hline $0-1.101$ & $48,48,47.9$ & $2,2,4$ & 0 \\
\hline $\begin{array}{l}1.101- \\
1.3\end{array}$ & $48,48.48,48.1$ & $1.9,2.01,4$ & 0.1 \\
\hline $\begin{array}{ll}1.501 & - \\
1.7 & \end{array}$ & $48,47.52,48.1$ & $2.01,1.9,4$ & 0.1 \\
\hline
\end{tabular}

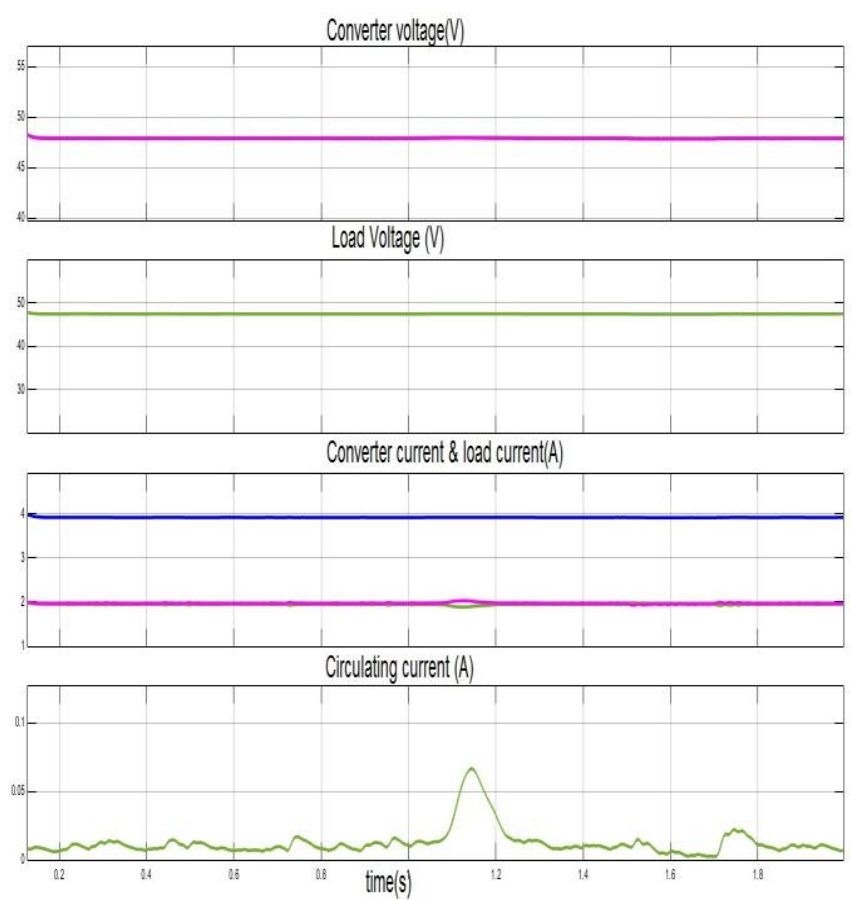

Fig -: 7. Simulation Result of with droop (a) converter output voltages (b) load voltage (c) converter output current and load current (d) circulating current. 
From the above simulation studies, it can be seen that droop control method gives proper load sharing with minimum circulating current and improves load voltage. By improving current sharing we can see that the power sharing has also been improved. Here, from the graphs it is obsereved that the circulating current has been reduced to $0.1 \mathrm{~A}$ from 1.9 A. Thus relatively equal current sharing accuracy is achieved by the parallel converters.

\section{CONCLUSION}

The performance of droop control method for parallel DCDC converter used in standalone photovoltaic wind system is studied in different cases. The entire energy conversion system has been designed in MATLAB/SIMULINK environment. Incremental conductance method of MPPT is used to track maximum output. The parallel DC- DC boost converter with sliding mode control technique is used. The $\mathrm{R}_{\text {droop }}$ values are calculated considering the effect cable resistance and implemented using virtual impedance method. For different irradiation of PV array and different wind speed the droop control the system is tested and verified. Based on the instantaneous condition the new $\mathrm{R}_{\text {droop }}$ value is introduced into the system, which will minimize the circulating current and gives proper sharing. This droop control technique can be used with any number of parallel connected converters.

\section{REFERENCES}

[1]. S.. Bull, "Renewable energy today and tomorrow," Proc. IEEE, vol. 89, no. 8, pp. 1216-1226, Aug. 2001.

[2]. C. Hua and C. Shen, "Study of maximum power tracking techniques and control of DC/DC converters for photovoltaic power system," 29th Annual IEEE Power Electronics Specialists Conference, pp. 86 93, 1998.

[3]. Y. Chuanan and Y. Yongchang, "An Improved HillClimbing Method for the Maximum Power Point Tracking in photovoltaic System," IEEE International Conference on Machine Vision and Human-Machine Interface, pp. 530 - 5332010.

[4]. S. Augustine, M. K. Mishra, and N. Lakshminarasamma, "Circulating current minimization and current sharing control of parallel boost converters based on droop index," in Proc. IEEE SDEMPED Conf., Aug. 2013, pp. 454-460.

[5]. S. Anand and B. Fernandes, "Modified droop controller for paralleling of dc-dc converters in standalone dc system," Power Electronics, IET, vol. 5, no. 6, pp. $782-789$, July 2012.

[6]. J.-W. Kim, H.-S. Choi, and B. H. Cho, "A novel droop method for converter parallel operation," IEEE Trans. Power Electron., vol. 17, no. 1, pp. 25-32, Jan. 2002.

[7]. S. Anand, B. G. Fernandes, and M. Guerrero, "Distributed control to ensure proportional load sharing and improve voltage regulation in low voltage dc microgrids," IEEE Trans. Power Electron., vol. 28, no. 4,pp. 1900-1913, Apr. 2013.
[8]. H.-H. Huang, C.-Y. Hsieh, J.-Y. Liao, and K.-H. Chen, "Adaptive droop resistance technique for adaptive voltage positioning in boost $\mathrm{dc}-\mathrm{dc}$ converters," IEEE Trans. Power Electron., vol. 26, no. 7, pp. 1920-1932, Jul. 2011.

[9]. Kai Strunz, Ehsan Abbasi, And Duc Nguyen Huu," Dc Microgrid For Wind And Solar Power Integration", IEEE Journal Of Emerging And Selected Topics In Power Electronics, Vol. 2, No. 1, March 2014

[10]. V. Nasirian, A. Davoudi, and F. L. Lewis, "Distributed adaptive droop control for dc microgrids," in Proc. IEEE 29th Annu. PEC, Mar. 2014, pp. 1147-1152.

[11]. M. J. Hossain, Hemanshu Roy Pota, M. Apel Mahmud," robust control for power sharing in microgrids with low-inertia wind and pv generators", IEEE transactions on sustainable energy, 2013

[12]. Guerrero, J. Vasquez, J. Matas, L. de Vicua, and M. Castilla,"Hierarchical control of droop-controlled ac and dc microgrids: A general approach toward standardization," IEEE Trans. Ind. Electron., vol. 58, no. 1, pp. 158-172, Jan. 2011. 